\title{
Selection of housekeeping genes for gene expression studies in the adult rat submandibular gland under normal, inflamed, atrophic and regenerative states
}

\author{
Nicholas Silver*, Emanuele Cotroneo, Gordon Proctor, Samira Osailan, \\ Katherine L Paterson and Guy H Carpenter
}

Address: Salivary Research Unit, Floor 17, Guy's Tower, King's College London, London, UK

Email: Nicholas Silver* - nick.silver@kcl.ac.uk; Emanuele Cotroneo - emanuele.cotroneo@kcl.ac.uk;

Gordon Proctor - gordon.proctor@kcl.ac.uk; Samira Osailan - samira.osailan@kcl.ac.uk; Katherine L Paterson - katherine.paterson@kcl.ac.uk;

Guy H Carpenter - guy.carpenter@kcl.ac.uk

* Corresponding author

Published: 17 July 2008

BMC Molecular Biology 2008, 9:64 doi:10.1186/1471-2199-9-64

This article is available from: http://www.biomedcentral.com/l47/-2199/9/64

(C) 2008 Silver et al; licensee BioMed Central Ltd.

This is an Open Access article distributed under the terms of the Creative Commons Attribution License (http://creativecommons.org/licenses/by/2.0), which permits unrestricted use, distribution, and reproduction in any medium, provided the original work is properly cited.

\begin{abstract}
Background: Real-time PCR is a reliable tool with which to measure mRNA transcripts, and provides valuable information on gene expression profiles. Endogenous controls such as housekeeping genes are used to normalise mRNA levels between samples for sensitive comparisons of mRNA transcription. Selection of the most stable control gene(s) is therefore critical for the reliable interpretation of gene expression data. For the purpose of this study, 7 commonly used housekeeping genes were investigated in salivary submandibular glands under normal, inflamed, atrophic and regenerative states.
\end{abstract}

Results: The program NormFinder identified the suitability of HPRT to use as a single gene for normalisation within the normal, inflamed and regenerative states, and GAPDH in the atrophic state. For normalisation to multiple housekeeping genes, for each individual state, the optimal number of housekeeping genes as given by geNorm was: ACTB/UBC in the normal, ACTB/YWHAZ in the inflamed, ACTB/HPRT in the atrophic and ACTB/GAPDH in the regenerative state. The most stable housekeeping gene identified between states (compared to normal) was UBC. However, ACTB, identified as one of the most stably expressed genes within states, was found to be one of the most variable between states. Furthermore we demonstrated that normalising between states to ACTB, rather than $U B C$, introduced an approximately 3 fold magnitude of error.

Conclusion: Using NormFinder, our studies demonstrated the suitability of HPRT to use as a single gene for normalisation within the normal, inflamed and regenerative groups and GAPDH in the atrophic group. However, if normalising to multiple housekeeping genes, we recommend normalising to those identified by geNorm. For normalisation across the physiological states, we recommend the use of $U B C$. 


\section{Background}

Saliva is secreted by three pairs of major salivary glands parotid, submandibular and sublingual - as well as numerous other minor salivary glands located around the mouth. Understanding atrophy and regeneration of salivary glands is clinically important, and studies have shown that acinar cells, which are lost from atrophic salivary glands, re-differentiate from remaining duct cells [13]. Studies have also shown that mitotic proliferation of remaining acinar cells participates in the increase of acini in the regenerative process of parotid glands where acinar cells remain $[4,5]$, and newly differentiated acinar cells proliferate actively in the regeneration of atrophic parotid glands in the absence of residual acinar cells [6]. In the submandibular gland, which differs histologically from the parotid gland, proliferation during regeneration has also been demonstrated [7]. Furthermore, recent observations of embryonic like ductal branch structures in regenerating submandibular tissue has led to a preliminary link between regeneration and embryonic development [8]. Which key gene expression signals induce apoptosis in atrophy and subsequent regeneration of the salivary gland still remains unclear. In order to help answer these questions, quantitative real time reverse transcription polymerase chain reaction (Q-RT-PCR) has been employed to study gene expression in the rat salivary gland model.

When comparing gene expression in different samples, it is essential to consider experimental variations such as amount of starting material, RNA extraction and reverse transcription efficiencies. To account for these, accuracy of Q-RT-PCR relies on normalisation to an internal control, often referred to as a reference or housekeeping gene. The prerequisite of a suitable housekeeping gene is that it should, of course, be adequately expressed in the tissue of interest, and that it shows minimal variability in expression between samples and under different experimental conditions used $[9,10]$.
Commonly used housekeeping genes in Q-RT-PCR include beta actin (ACTB), glyceraldeyde-3-phosphate dehydrogenase (GAPDH), ribosome small subunit (18S) ribsosomal RNA (rRNA), Ubiquitin C (UBC), hypoxanthine guanine phosphoribosyl transferase (HPRT), succinate dehydrogenase complex, subunit A (SDHA) and Tyrosine 3-monooxygenase/tryptophan 5-monooxygenase activation protein, zeta polypeptide (YWHAZ) [1113]. However, many of these control genes can show unacceptable variability in expression [14-19]. An example of this was shown by Torres et al [20], where mRNA levels of GAPDH were found to be androgen-dependent and varied according to the experimental conditions. Furthermore, Suzuki et al [21] discussed the uses and pitfalls of using 'classical' control genes such as GAPDH and ACTB. Here, cases were highlighted in which these control genes had been shown to be significantly modulated, and as a result, precautionary measures were suggested, such as the use of more than one control gene for normalisation. Without appropriate normalisation, expression profiles of target genes will likely be misinterpreted [14-18]. With increased gene expression profiling in pre-clinical genetic research, in parallel with ambitions for improved oral health, a need for accurate control genes for the various physiological states of the rat submandibular gland has emerged; however, appropriate studies in this area have not yet been conducted.

In this study, we chose to investigate a panel of 7 housekeeping genes (Table 1) in the adult rat submandibular gland in normal, inflamed, atrophic and regenerative states.

These different states were induced using intra-oral duct ligation, a well characterised surgical technique $[22,23]$, whereby the submandibular duct is clipped (ligated) to induce initially inflammation, after 2 wks extensive atrophy, and subsequently removed (de-ligated) to induce regeneration $[8,22-24]$. Specifically, the states were

Table I: Panel of 7 candidate housekeeping genes selected

\begin{tabular}{|c|c|c|c|}
\hline Gene symbol & Gene Name & mRNA accession number & Function \\
\hline ACTB & Beta-actin & NM 031144 & Cytoskeletal structural protein \\
\hline ARBP & Acidic ribosomal phosphoprotein PO & NM 022402 & $\begin{array}{l}\text { Ribosomal structural protein/nucleic acid } \\
\text { binding }\end{array}$ \\
\hline GAPDH & Glyceraldeyde-3-phosphate dehydrogenase & NM 017008 & Glycolytic enzyme \\
\hline HPRT & Hypoxanthine guanine phosphoribosyl transferase & NM 012583 & $\begin{array}{l}\text { Involved in the metabolic salvage of purines } \\
\text { in mammals }\end{array}$ \\
\hline SDHA & $\begin{array}{l}\text { Succinate dehydrogenase complex, subunit A, } \\
\text { flavoprotein }\end{array}$ & NM 130428 & Involved in the oxidation of succinate \\
\hline UBC & Ubiquitin C & NM 017314 & Possible involvement in protein catabolism \\
\hline YWHAZ & $\begin{array}{l}\text { Tyrosine } 3 \text {-monooxygenase/tryptophan } 5 \text { - } \\
\text { monooxygenase activation protein, zeta polypeptide }\end{array}$ & NM 013011 & Protein domain specific binding \\
\hline
\end{tabular}


defined as: unoperated (normal), $24 \mathrm{hr}$ ligated (inflamed), 2 wk ligated (atrophic), and $2 \mathrm{wk}$ ligated glands followed by 3 days of de-ligation (regenerative). Furthermore, we evaluated a selected number of housekeeping genes via normalisation of a target gene, here $S M G B[25,26]$, a gene which encodes a secretory protein identified in the development and regeneration of the submandibular gland [8].

\section{Results}

\section{Gland Weights}

In order to provide evidence that the surgical procedures carried out in the ligation/de-ligation model were successful, the weight of the rat submandibular glands were measured and recorded. Following 24 hrs of ligation, submandibular glands showed an increased weight of approximately $40 \%(\mathrm{P}<0.01)$ when compared to the unoperated glands (Figure 1). Following 2 wks of ligation, submandibular glands were less than 50\% $(P<0.001)$ of the unoperated controls. However, 2 wk ligated +3 day de-ligated glands showed a small but significant increase in weight $(\mathrm{P}<0.05)$ when compared with the glands ligated for 2 wks.

\section{Histology}

When compared with the unoperated normal glands, the increased weight of the $24 \mathrm{hr}$ ligated glands was accompanied by changes in the histology as illustrated by haematoxylin-and-eosin (H\&E) and alcian blue-periodic acidSchiff (AB/PAS) staining (Figure 2a-d). Compared with the unoperated submandibular gland, the $24 \mathrm{hr}$ ligated

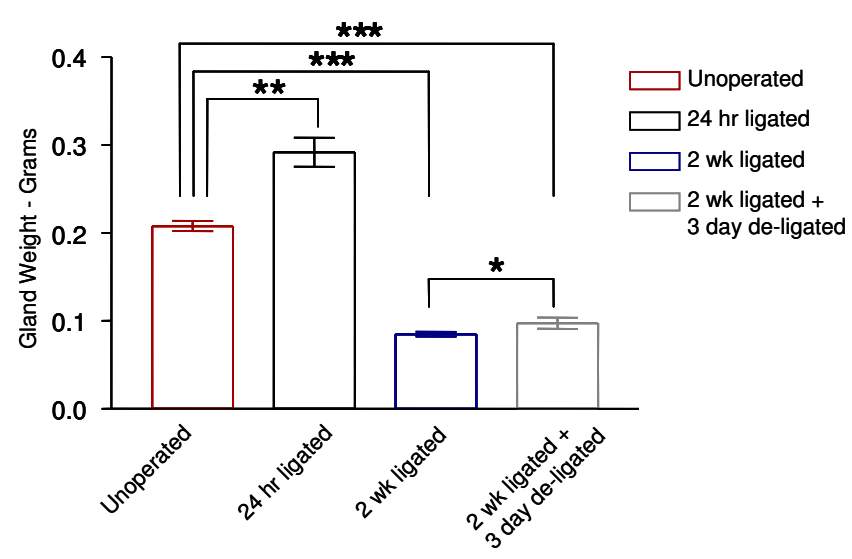

Figure I

Mean weight \pm SEM of unoperated, $24 \mathrm{hr}$ ligated, 2 wk ligated and 2 wk ligated +3 day de-ligated submandibular glands. * indicates statistical significance $\mathrm{P}<$ 0.05 , $* * P<0.0 \mathrm{I}$ and $* * * \mathrm{P}<0.00 \mathrm{I}$ and were calculated using the Student's t-test $(n=5)$. gland appeared less tightly packed and contained large numbers of infiltrating inflammatory cells. These cells were most prominent in the stroma of the gland although they were also present within the interstitial space between acini and ductal units. The infiltrating cells appeared to be mostly neutrophils and macrophages (based on cell size and shape) although no detailed analysis was attempted. In addition, blood vessels and salivary striated duct lumena appeared dilated in the ligated gland compared with the normal gland. In the 2 wk ligated glands, when compared with the unoperated glands, they showed increased inflammatory cell infiltration in the connective tissue between the lobules and among the parenchymal elements (Figure $2 \mathrm{e}-\mathrm{f}$ ). H\&E staining of the 2 wk ligated glands suggested the acini had almost completely disappeared, whilst many residual duct like structures were still visible with considerably dilated lumens. In addition, $\mathrm{AB} / \mathrm{PAS}$ showed an almost complete absence of secretory granules from both acini and ductal cells in the 2 wk ligated glands. The stain also showed the presence of some secretory products in the lumen of the ducts (Figure 2f) in contrast to the de-ligated glands where the $\mathrm{AB} / \mathrm{PAS}$ staining in the lumen was lost (Figure $2 \mathrm{~h}$ ).

In a similar fashion to the 2 wk ligated, the 3 day deligated glands, when compared with the unoperated, showed increased inflammatory cell infiltration in the connective tissue between the lobules and among the parenchymal elements (Figure $2 \mathrm{~g}-\mathrm{h}$ ). The H\&E staining showed that some acini, mostly on the edge of the lobules had recovered some of their size and the lumen of the ducts appeared less obvious. In addition, embryonic type developmental branch structures were apparent as indicated (Figure $2 \mathrm{~g}$ - double arrow heads). Further evidence from the AB/PAS staining showed that several acini, mainly located at the edges of the lobules had recovered some of their glycoprotein content.

\section{RNA Quality}

RNA purity was measured using the NanoDrop ${ }^{\circledR}$ Spectrophotometer (NanoDrop Technologies). The mean ( \pm SEM) $A_{260 / 280}$ ratio of RNA samples was $2.07 \pm 0.04$ (range from 1.96-2.12) and reflected pure and protein free RNA. The mean $\left( \pm\right.$ SEM) $A_{260 / 230}$ ratio was $1.98 \pm 0.21$ (range from $1.63-2.23$ ) and indicated the RNA was phenol and ethanol free. The RNA integrity as an essential quality criterion was characterised by the RNA integrity number (RIN) [27], measured on the Agilent 2100 Bioanalyzer (Agilent Technologies). The mean ( \pm SEM) RIN value of all RNA samples was $8.7 \pm 0.53$ (range from 7.8-9.5).

\section{Q-RT-PCR efficiency and intra- and inter- assay variability} Quantitative real-time PCR was used to measure the RNA transcription level of a number of candidate housekeeping genes (Table 1). To compare different RNA transcrip- 

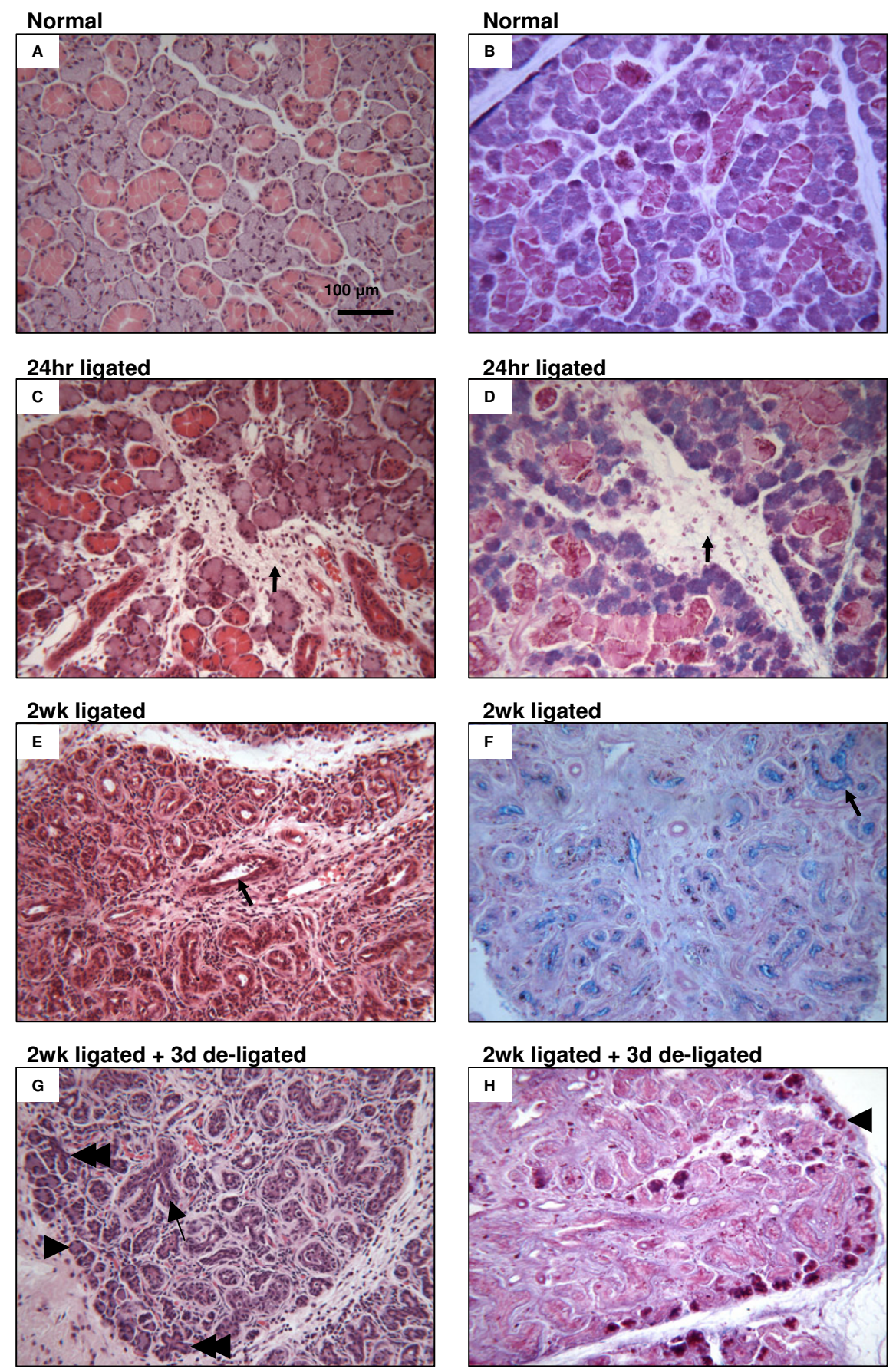

$H \& E$

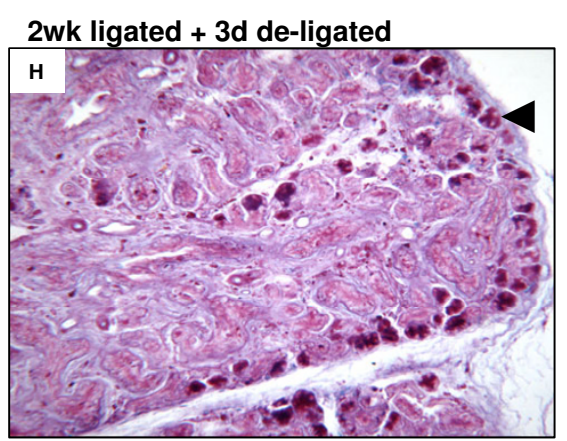

AB/PAS

\section{Figure 2}

A-H: H \& E and AB/PAS staining. (A \& B) Control: Normal unoperated submandibular gland showing the typical appearance of acini and ductal cells. (C \& D) $24 \mathrm{hr}$ ligated: Large numbers of infiltrating inflammatory cells in the increased stroma and interstitial spaces (arrows). (E) 2 wk ligated - H \& E: Luminal dilation of ducts (arrow), absence of acini, and extensive inflammation. (F) 2 wk ligated - AB/PAS: Loss of cellular secretory granules and presence of material in the lumen of ducts (arrow). (G) 3 days following removal of 2 wk ligation - H \& E: Some acini (arrow head) and ductal cells (arrow) have recovered some of their size, while acinar-ductal branch structures are also visible (double arrow head). $(\mathrm{H}) 3$ days following removal of 2 wk ligation - AB/PAS: Some acini have recovered their glycoprotein content (arrow head). 
tion levels, the $\mathrm{Ct}$ values were compared directly. The $\mathrm{Ct}$ is defined as the number of cycles needed for the fluorescence to reach a specific threshold level of detection and is inversely correlated with the amount of template nucleic acid present in the reaction [28]. To ensure optimal comparability between the PCR assays, efficiency of each individual assay was determined by measuring serial dilutions of cDNA from a control (unoperated) submandibular gland in duplicate. Only Ct values $<40$ were used for calculation of the PCR efficiency from the given slope generated in the 7500 system software v1.3.1 according to the equation: PCR efficiency $=\left(10^{[-1 / \text { slope }]}-1\right) \times 100$. All PCR assays displayed efficiencies between 90 and 102\% (Table 2 ). Intra and inter-assay variation was investigated in three independent runs performed on three consecutive days. Intra-assay variation was $<0.4 \%$ and inter-assay variation $<1.0 \%$.

\section{Expression profiling of housekeeping genes}

Primers were selected for commonly used housekeeping genes for a total of 7 control genes - see Table 2 for details. Particular attention was paid to selecting genes that belong to different functional classes, which significantly reduces the chance that genes might be co-regulated. The expression level of the 7 internal control genes was determined in 20 submandibular gland samples, comprising of 4 different groups - 5(unoperated samples), 5(24 hr ligated), 5(2 wk ligated) and 5(2 wk ligated +3 day deligated) (Figure 3).

\section{Stability of housekeeping genes within sample groups}

Stability of the 7 housekeeping genes was first assessed for each sample group. Gene expression levels were measured by real-time PCR and the expression stabilities were evaluated by the two most commonly used software based methods: (1) geNorm [29] and (2) NormFinder [30]. GeNorm uses a gene-stability measure $M$, which is defined as the average pairwise variation between a particular gene and all other control genes and calculates the optimal number of genes necessary for normalisation of a target gene. The NormFinder program uses a model-based approach for estimation of expression and enables the identification of the single best gene as well as giving a ranking order. Based on the $M$ value, all housekeeping genes in all but one group (the 2 wk ligated) reached the geNorm arbitrary cut-off level of 0.5 for stability (Table 3 ). This suggests that the use of any of these housekeeping genes for normalisation is warranted. For the 2 wk ligated group, those genes which were within the stable 0.5 cutoff limit were ACTB, HPRT and GAPDH (Table 3). The optimal number of housekeepers for normalisation as given by geNorm can be seen in Table 4 . These were as follows: $A C T B / U B C$ in the unoperated control group, ACTB/YWHAZ for the $24 \mathrm{hr}$ ligated, - ACTB/HPRT for the $2 \mathrm{wk}$ ligated group and - ACTB/GAPDH for the $2 \mathrm{wk}$ ligated +3 day de-ligated group. NormFinder identified HPRT as the single most stable gene for the unoperated and $24 \mathrm{hr}$ ligated groups, GAPDH for the $2 \mathrm{wk}$ ligated, and HPRT for the $2 \mathrm{wk}$ ligated +3 day de-ligated group (Table $4)$.

\section{Stability of housekeeping genes compared to normal tissue} Stability of the 7 housekeeping genes was further assessed in the 24 hr ligated, $2 \mathrm{wk}$ ligated and $2 \mathrm{wk}$ ligated +3 day de-ligated groups in comparison to the unoperated state. Expression stability was evaluated by (1) RNA normalised gene expression (2) The Mann-Whitney-U Test and Equivalence statistics (3) Normalisation to the geometric mean of selected housekeeping genes (4) NormFinder. Following normalisation to total RNA, gene expression levels were expressed relative to the unoperated group (Figure 4). The top 3 most stable housekeeping genes were: $U B C$, $S D H A$ and $A R B P$ for all states. Following statistical analysis using the Mann-Whitney-U Test, only $U B C$ and SDHA for the $24 \mathrm{hr}$ ligated, $2 \mathrm{wk}$ ligated and $2 \mathrm{wk}$ ligated +3 day de-ligated states showed no change from the unoperated control group ( $>0.05)$ (Figure 4$)$. The equivalence assessment was then carried out to look for similarities between the groups. In the present case, the variables that showed statistically significant differences indicated an approximately $10 \%$ change. Thus, equivalence cannot be assumed for the other variables where differences might be outside this level. Applied to UBC and SDHA, the variables for which equivalence testing was required, the upper limit of the $95 \%$ confidence intervals for UBC did not reach the $10 \%$ level of reduction for the unoperated vs 2 wk ligated \& 2 wk ligated +3 day de-ligated groups, implying equivalence. This was also true of SDHA for

Table 2: Characteristics of primer and probe sets

\begin{tabular}{|c|c|c|c|c|}
\hline Gene symbol & Context Sequence & Amplicon length & Efficiency (\%) & Primer \& Probe Set \\
\hline ACTB & СTTCCTGGGTATGGAATCCTGTGGC & 91 & 100 & Assay by design (ABI) \\
\hline ARBP & TGGCCAATAAGGTGCCAGCTGCTGC & 100 & 90 & Assay by design (ABI) \\
\hline GAPDH & CGGGAAACCCATCACCATCTTCCAG & 87 & 102 & Assay by design (ABI) \\
\hline HPRT & ACTGGAAAGAACGTCTTGATTGTTG & 100 & 94 & Assay by design (ABI) \\
\hline SDHA & CATACTGTTGCAGCACAGGGAGGTA & 59 & 98 & Assay by design (ABI) \\
\hline UBC & TGGGTTTGATGGGGAGGTGTCTTAG & 88 & 98 & Assay by design (ABI) \\
\hline YWHAZ & GCAACGACGTACTGTCTCTTTTGGA & 104 & 102 & Assay by design (ABI) \\
\hline
\end{tabular}



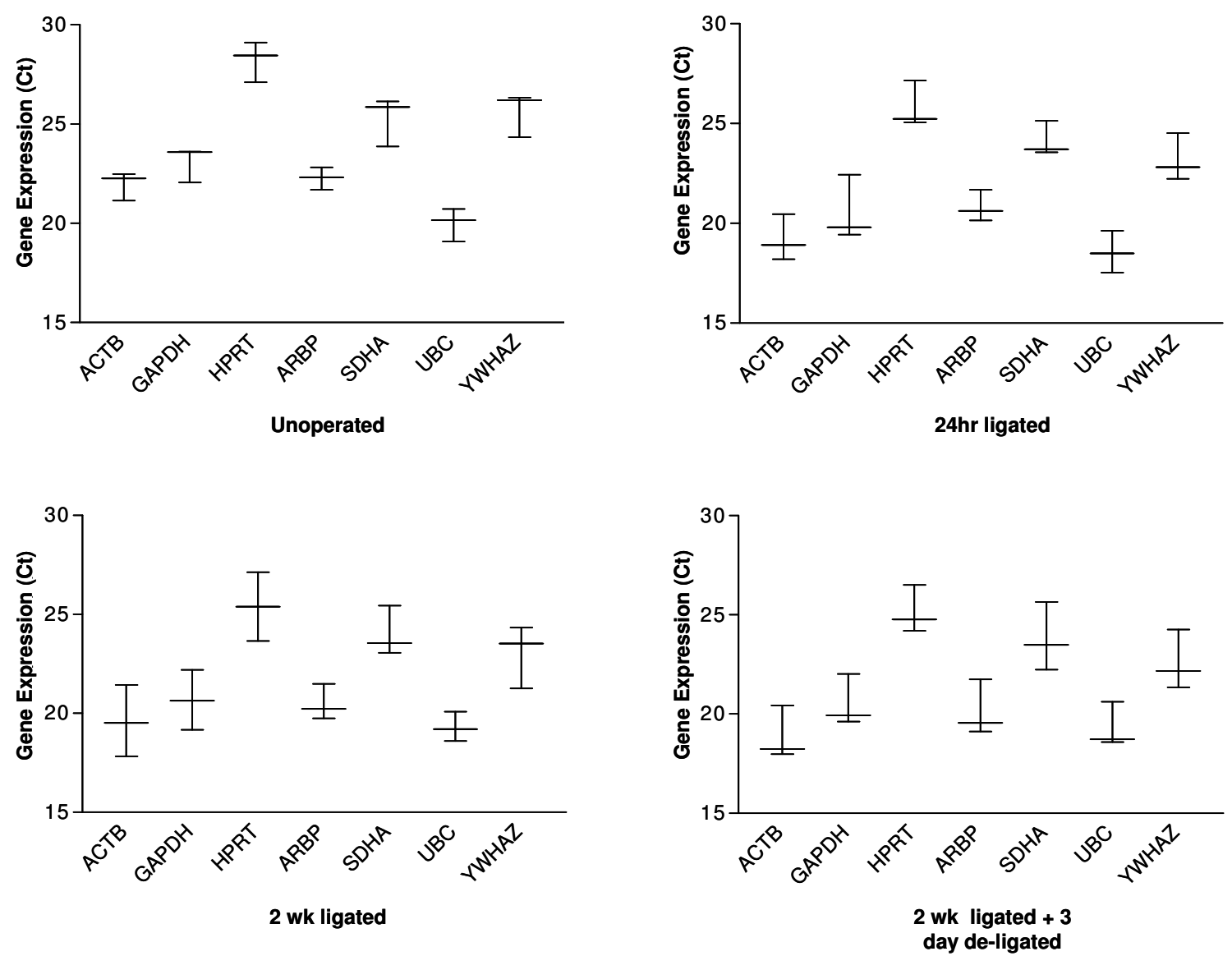

\section{Figure 3}

Q-RT-PCR cycle threshold $(C t)$ values for 7 candidate housekeeping genes among 20 rat submandibular samples. Gene expression levels are shown as medians (lines) and ranges (whiskers). Candidate housekeeping genes include ACTB, GAPDH, HPRT, ARBP, SDHA, UBC and YWHAZ.

Table 3: Housekeeping gene rankings for each tissue state

Housekeeping genes ranked in order of their expression stability

\begin{tabular}{llllllll}
\hline Unoperated & $\mathbf{M}$ & $\mathbf{2 4} \mathbf{h r}$ ligated & $\mathbf{M}$ & $\mathbf{2}$ wk ligated & $\mathbf{M}$ & $\mathbf{2}$ wk ligated + 3 day de-ligated \\
\hline ARBP & 0.434 & SDHA & 0.496 & SDHA & 0.792 & SDHA & $\mathbf{M}$ \\
SDHA & 0.364 & GAPDH & 0.417 & YWHAZ & 0.641 & YWHAZ & 0.387 \\
YWHAZ & 0.328 & ARBP & 0.352 & UBC & 0.562 & ARBP \\
GAPDH & 0.243 & UBC & 0.278 & ARBP & 0.505 & HPRT & 0.272 \\
HPRT & 0.196 & HPRT & 0.213 & GAPDH & 0.359 & UBC & 0.207 \\
\hline ACTB-UBC & 0.155 & ACTB-YWHAZ & 0.136 & ACTB-HPRT & 0.226 & ACTB-GAPDH \\
\hline
\end{tabular}

Increasing stability from top to bottom; the two most stable control genes in tissue state, for example ACTB and UBC in unoperated tissue, cannot be ranked in order because of the required use of gene ratios for gene stability measurements. $M$ is defined as the control gene-stability measure. 


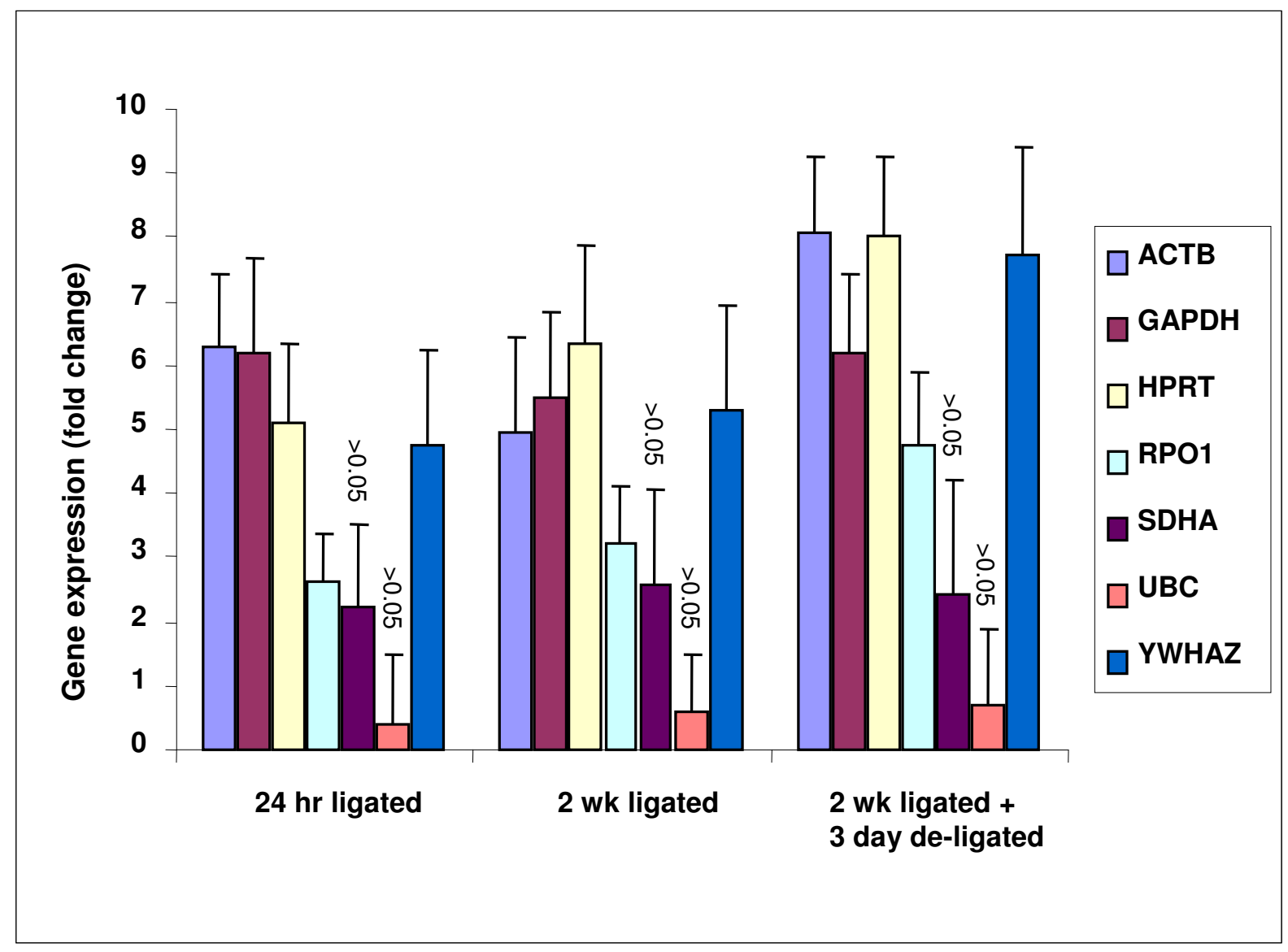

Figure 4

Candidate housekeeping gene expression normalised to total RNA and relative to the normal state. In the figure $\mathrm{n}=5$ per experimental group and error bar represent $\pm S D$. The Mann Whitney- $U$ test was used to test for differences between sample sets. UBC and SDHA were the only two genes which showed no significant difference $(>0.05)$ throughout the different groups when compared with the control group.

comparison of the unoperated vs $24 \mathrm{hr}$ ligated group. However, the other comparisons all exceeded a $10 \%$ reduction and could not be regarded as equivalent. Using these methods as an indicator of housekeeping gene intergroup stability, we then normalised the data against the geometric mean of the expression levels of $U B C$ and SDHA. A comparison of the geometric normalised expression of each of the housekeeping genes further demonstrated the stability of $U B C$ and $S D H A$ relative to the other genes within the relevant groups (Figure 5, Table 5). NormFinder has the option of defining groups within the samples and was used to further evaluate housekeeping gene inter-group stability. Based on the best combination of two housekeeping genes, the NormFinder program suggested normalising to $U B C$ and HPRT when comparing the $24 \mathrm{hr}$ ligated/2 wk ligated with the unoperated state, and $U B C$ and GAPDH when comparing the 2 wk ligated + 3 day de-ligated and unoperated state - see Table 5 .

\section{Evaluation and validation of selected candidate housekeeping genes using SMGB}

Following identification of the most stable housekeeping genes from the full panel, a method was needed for their evaluation. As described previously by our laboratory [8], a correlation between the state of the submandibular gland and expression of the protein Smgb has been shown. More specifically, following 2 wks of ligation, a decrease in Smgb protein levels were seen when compared with unoperated glands. However, following 3 days of deligation, although a decrease in Smgb protein levels were 
Table 4: Summary and comparison of the top candidate housekeeping genes for each gland state identified by geNorm and NormFinder

\begin{tabular}{lll}
\hline & geNorm & NormFinder \\
\hline Unoperated & UBCIACTB & HPRT \\
24 hr ligated & YWHAZIACTB & HPRT \\
2 wk ligated & HPRT/ACTB & GAPDH \\
2 wk ligated + 3 day de-ligated & GAPDHIACTB & HPRT \\
& & \\
\hline
\end{tabular}

For the geNorm program, determination of the optimal number of control genes for normalisation is made. This is calculated through pairwise variation analysis through which Vandesompele et al proposed 0.15 as a cut off value. This optimal number of housekeeping genes is in the order given by the program.

still seen when compared with normal glands, an increase was seen relative to the atrophic glands. Therefore, we expected these observations to be mirrored at the mRNA level.

Consequently, gene expression analysis of $S M G B$ in the 3 surgically induced groups was compared for normalisation using $A C T B$, one of the least stable housekeeping genes identified, and one of the highest scoring genes (most stable), UBC. This was carried out using the relative expression software tool $\left(\mathrm{REST}^{\oplus}\right)$ [31], developed for group-wise comparison and statistical analysis of relative expression results. When normalised to $A C T B, S M G B$ was down-regulated in the $2 \mathrm{wk}$ ligated sample group (in comparison to the normal unoperated group) by approximately 111 fold, $P=0.017$ (Figure 6). However, in the 2 wk ligated + 3 day de-ligated group, although SMGB was down-regulated by approximately 29 fold, $\mathrm{P}=0.038$, an increase of approximately 3.8 fold was seen in comparison to the 2 wk ligated group (although this was not statistically significant, $\mathrm{P}=0.388$ ). When normalised to the more stable $U B C, S M G B$ was down-regulated in the $2 \mathrm{wk}$ ligated sample group (in comparison to the unoperated group) by approximately 38 fold, $\mathrm{P}=0.016$ (Figure 6 ). In the 2 wk ligated +3 day de-ligated group, $S M G B$ was down-regulated by approximately 11 fold, $\mathrm{P}=0.044$, however, an increase of approximately 3.6 fold was seen in comparison to the $2 \mathrm{wk}$ ligated group (although again, this was not statistically significant, $\mathrm{P}=0.388$ ). Based on these results, evaluation of the two housekeeping genes for normalisation indicated that although the pattern of gene expression was identified as being similar to the protein expression using either $A C T B$ or $U B C$, there was an approximately 3 -fold under-estimation of target gene expression (SMGB) when normalising against ACTB when compared with $U B C$.

\section{Discussion}

Characterisation of atrophy, followed by the early regeneration of the rat submandibular gland following intraoral duct ligation $[22,23]$ is crucial to fully understanding the genetic mechanisms leading to the recovery of various cellular elements, and ultimately their secretory ability. In addition, characterisation of these genetic mechanisms may not just be restricted to atrophy and regeneration of the rat submandibular gland, but may also have implications for the wider field of regenerative biology. In order to accurately detect and track these changes in gene expression level at the various stages of atrophy and regeneration, a sensitive and reproducible method is needed. Quantitative real-time PCR fulfils these requirements, in that it is one of the most established and sensitive methods available with which to detect gene transcript levels. As highly accurate quantitative gene expression data in QRT-PCR based gene expression studies are normalised relative to an internal control, it is critical to choose an appropriate control gene(s) for normalisation, so as not to misinterpret the expression profile of a target gene $[14,17,32,33]$. Since it is likely that no single control gene is stable for all studies [10], the selection of an appropriate control gene is necessary for each new experimental system, especially where complex tissues are involved.

To the best of our knowledge, there has not yet been a detailed evaluation of housekeeping genes in the rat submandibular gland. Moreover, there has not been a detailed study under different states of inflammation, atrophy and regeneration. In recent years, there have been a number of research papers and reviews evaluating the selection and effect of controls on normalised gene expression data in various rat tissues. One recent publication by Cai et al [34] involved the validation of housekeeping genes in a panel of rat tissues using low density arrays. Other studies in the rat model have focused on more specific tissues, including the retina [35], fetal brain [36], cortex and hippocampus [37] and liver [11]. However, none of these in depth housekeeping gene studies in the rat model have included the rat submandibular gland. Although no in depth studies are apparent in the submandibular gland tissue, there have been numerous research papers which have used single housekeeping genes to control for gene expression in this tissue. These have included the use of $18 \mathrm{~S}$ rRNA [38,39], GAPDH [40] and АСТВ $[41,42]$ for normalisation. Nevertheless, it is not always clear on what basis these various control genes were chosen, and of the various ones used, which were the most appropriate. As a consequence, in this study, we evaluated the gene expression stability of 7 commonly used 'classical' housekeeping genes in the rat submandibular gland, and furthermore, assessed the levels in states of inflammation (24 hr ligation), atrophy (2 wk ligation) 


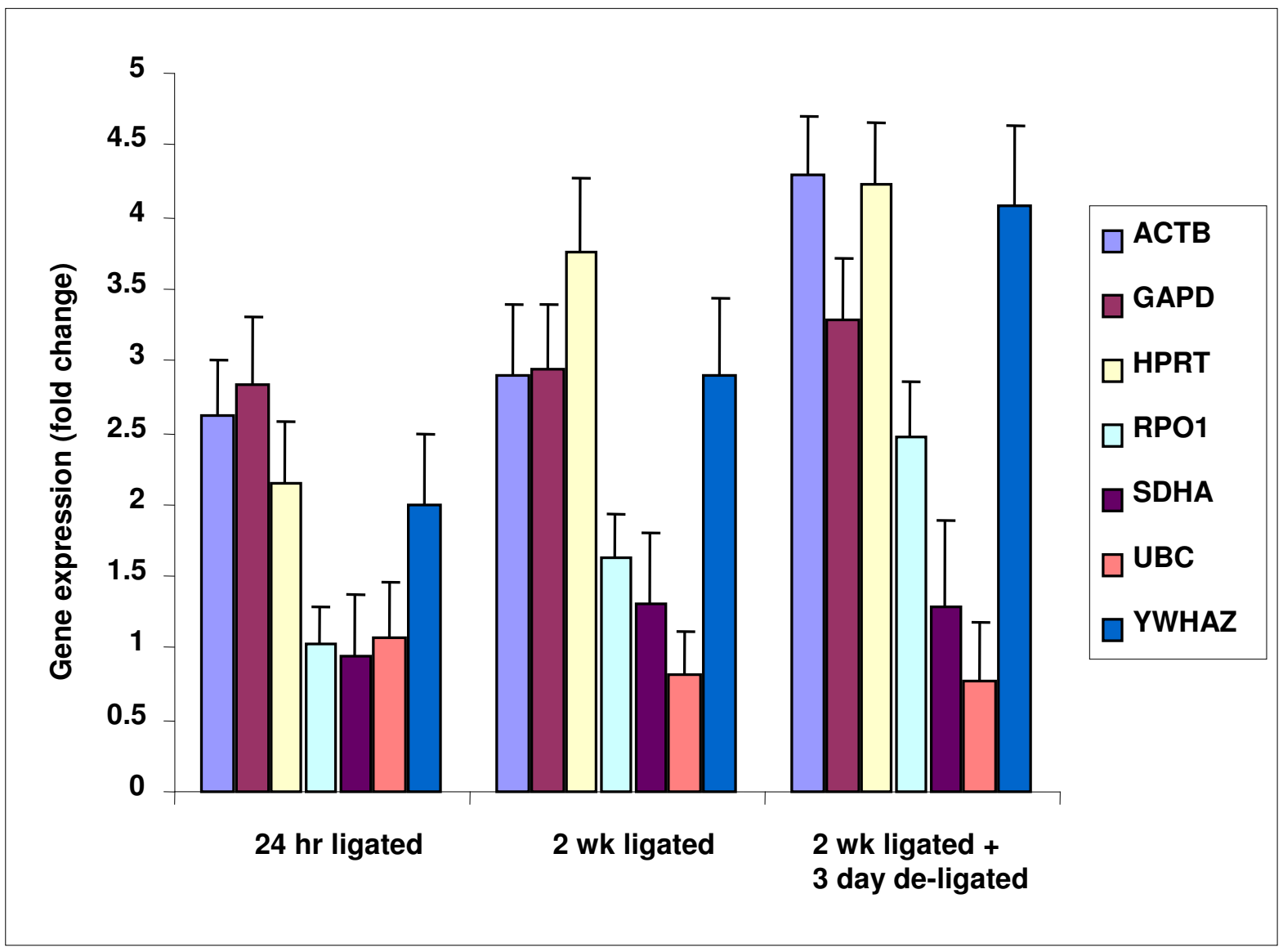

Figure 5

Candidate housekeeping gene expression following geometric normalisation and relative to the normal state. Candidate housekeeping genes were normalised by dividing the relative expression value by the geometric mean of the expression levels of the two selected housekeeping genes UBC and SDHA.

and regeneration ( $2 \mathrm{wk}$ ligation followed by 3 days of deligation).

In order to effectively assess the housekeeping gene expression levels, it was important to confirm the surgical procedures had been carried out successfully and this was done via inspection of both gland weight and histology.
Ligation was confirmed in the $24 \mathrm{hr}$ ligated glands, indicated by their heavier weight when compared with the normal glands (Figure 1). These heavier gland weights corresponded with the oedematous appearance, which was partially due to the build up of saliva, as well as due to inflammation related oedema seen in the histology as inflammatory infiltrate [24] (Figure $2 \mathrm{c}-\mathrm{d}$ ). In the $2 \mathrm{wk}$

Table 5: Summary and comparison of the top candidate housekeeping genes when compared to the unoperated state identified by geometric normalisation and NormFinder

\begin{tabular}{lll}
\hline & Normalised (Geometric mean) & NormFinder \\
\hline Normal vs $24 \mathrm{hr}$ ligated & UBC, ARBP & UBC, HPRT \\
Normal vs 2 wk ligated & UBC, SDHA & UBC, HPRT \\
Normal vs 2 wk ligated +3 day de-ligated & UBC, SDHA & UBC, GAPDH \\
\hline
\end{tabular}




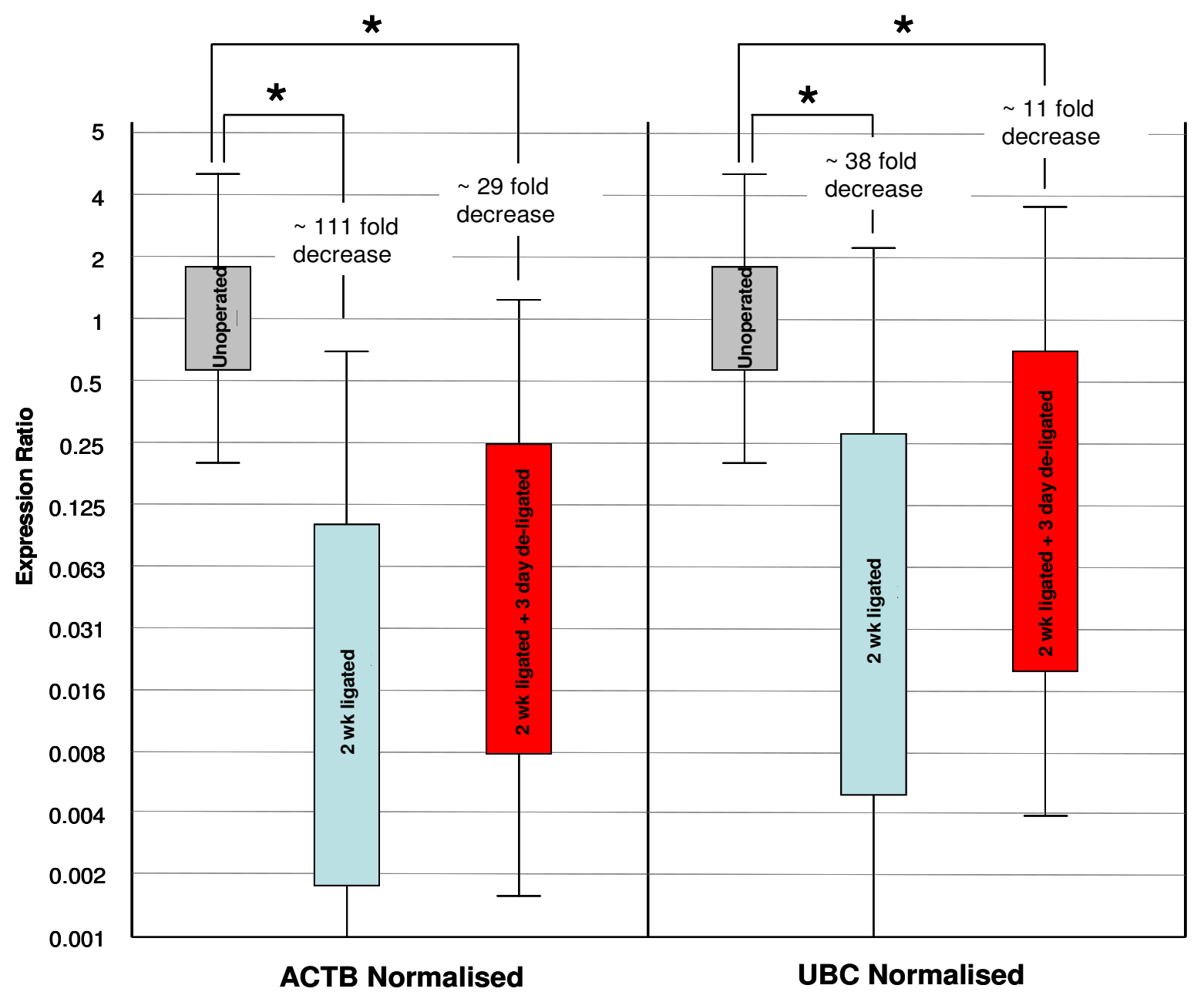

\section{Figure 6}

Whisker box plots showing SMGB gene expression in terms of expression ratios. The results are expressed as box plots of mRNA expression relative to the normal control state after normalisation to either ACTB or UBC. Shown are the $25 \%$ to $75 \%$ response ranges (top and bottom lines of boxes) and minima and maxima (whiskers). Asterisks indicate a significant change $(p<0.05)$ in SMGB expression in the 2 wk ligated and 2 wk ligated +3 day de-ligated states when compared to the normal state. Changes in expression are also indicated in terms of fold change relative to the normal control level.

ligated glands, in addition to significant reduction in gland weight when compared to the normal unoperated glands, dramatic morphological changes occurred (Figure $2 \mathrm{e}-\mathrm{f}$ ), all of which suggested that the ligation of the excretory ducts was successful and consequently atrophy of the gland had ensued - this was as previously described in the literature [22,43-45]. After two weeks of ligation followed by 3 days of de-ligation, the weight of the de-ligated glands increased significantly over those undergoing just 2 wk ligation. In addition, acini cells, mostly on the edge of the gland lobules recovered their size (Figure $2 \mathrm{~g}-\mathrm{h}$ ). Furthermore, absence of secretory material in the lumen of the gland ducts suggested reactivation of salivary flow [8]. Having confirmed all procedures, mRNA transcript levels of the different submandibular groups could be measured and compared with confidence.

Housekeeping gene expression stability 'within' sample groups was evaluated by (1) GeNorm applet and (2) NormFinder. The principle that the expression ratio of two ideal control genes should be identical across experimental groups is well established [29,46]. Based on this principle and using the geNorm program [29], we found that despite the dramatic morphological changes that had occurred in the submandibular tissue, the variability in housekeeping gene expression in each individual gland group was relatively low. This stability was reflected by the $M$ values calculated for the 7 candidate housekeeping 
genes, which were all under the arbitrary threshold of 0.5 in the unoperated, $24 \mathrm{hr}$ ligated and $2 \mathrm{wk}$ ligated +3 day de-ligated groups; except for the $2 \mathrm{wk}$ ligated group in which only ACTB, HPRT, GAPDH were below this cut off value. The reasons for this are not clear but probably reflect the extremely different histology of an atrophic exocrine gland. As previously described, normalisation to a single housekeeping gene can lead to erroneous results $[14,17,32,33]$. Vandesompele et al [29] concluded that in order to measure gene expression levels accurately, normalisation by multiple housekeeping genes instead of one can be used. Consequently, a normalisation factor (NF) can be calculated, which is based on the geometric mean of a recommended minimum of housekeeping genes. Therefore, depending on practicality, we recommend using the geometric average of the two highest scoring housekeeping genes, as suggested by the geNorm program, here: $A C T B / U B C$ in the unoperated group, - ACTB/ YWHAZ for the $24 \mathrm{hr}$ ligated, - ACTB/HPRT for the $2 \mathrm{wk}$ ligated group and - ACTB/GAPDH for the 2 wk ligated + 3 day de-ligated group. Although expression stability analysis by NormFinder identified different top-ranking genes to geNorm (Table 4), the top ranking genes identified by NormFinder for each sample group were all identified by geNorm as being stable (according to the stability measure $\mathrm{M}$ ). These were HPRT as the single most stable gene for the unoperated and $24 \mathrm{hr}$ ligated groups, GAPDH for the 2 wk ligated, and HPRT for the 2 wk ligated +3 day deligated group. This was also reported in a recent study by Lyng et al, whereby a different rank order between the geNorm and NormFinder programs was observed during identification of housekeeping genes in breast carcinomas. This difference in top-ranking between the two programs is likely reflective of the different embedded methods used. GeNorm uses a pairwise comparison approach of 'pairs of genes', whereas NormFinder uses a model-based approach for direct estimation of expression variation, as well as taking into account sample subgroups. Based on these results, if normalising to multiple housekeeping genes, we suggest using those identified by geNorm. However, if normalising to a single housekeeping gene, we suggest using those identified by NormFinder, as they also agreed with those identified by geNorm as being stable.

Housekeeping gene expression stability 'between' sample groups was evaluated by (1) Normalising to total RNA (2) The Mann-Whitney-U Test and Equivalence statistics (3) Normalisation to the geometric mean of selected housekeeping genes (4) NormFinder. GeNorm was not used in this part of the analysis, as it does not provide the option of clearly defining sub-groups. However, NormFinder has an option to define sub-groups, making it more appropriate for comparison of the surgically induced states with the normal state. Following normalisation to total RNA, relative expression of the housekeeping genes in each group when compared with the normal unoperated group suggested the top 3 most stable genes to be UBC, SDHA and ARBP. Analysis was then carried out using the MannWhitney-U Test to look for statistically significant variation between the raw $\mathrm{Ct}$ values of the different groups. This analysis suggested that only the two genes $U B C$ and $S D H A$ showed no significant difference $(>0.05)$ for the 24 $\mathrm{hr}$ ligated, $2 \mathrm{wk}$ ligated and $2 \mathrm{wk}$ ligated +3 day de-ligated groups when compared with the unoperated group, therefore discounting the other genes in the panel as being sufficiently stable. Similarity between the groups was then assessed for UBC and SDHA by testing for equivalence. Here, equivalence was indicated for UBC in the unoperated vs 2 wk ligated and 2 wk ligated +3 day de-ligated states. This was also true for SDHA for comparison between the unoperated and 2 wk ligated group. In situations where no optimal normalisation gene has been found, it may be prudent to normalise the data using the geometric mean based on multiple normalisation genes rather than a single gene [30]. The rationale for this is that the variation in the average of multiple genes is smaller than the variation in individual genes. Following this rationale, normalising the relative gene expression data to the geometric mean of UBC and SDHA further demonstrated the level of stability of these genes when compared with genes displaying the most variability, for example, ACTB, GAPDH and HPRT. In addition to using these more basic methods to detect stability, NormFinder was further incorporated into the analysis. Although NormFinder analysis of the sub-groups suggested $U B C$ for use in normalisation, it also suggested using HPRT in combination. However, HPRT had previously been identified as being one of the more variable housekeeping genes between groups. This is likely explained by the fact that NormFinder uses a different approach to identifying stable genes. As mentioned previously, it uses a model-based approach for estimation of expression variation, uses definitions of sub-groups within a sample set, and has the build in ability to identify co-regulated genes based on the similarity of their expression profiles. It is possible therefore, that the NormFinder program has chosen the two genes, UBC and HPRT, on the basis that they show minimal co-expression. Nevertheless, having used multiple methods for stability analysis of the housekeeping gene panel between groups, $U B C$ was consistently identified as being the most stable. We would therefore suggest the use of $U B C$ when normalising between groups.

For the purpose of our gene expression studies in the submandibular gland, it is important that we are able to normalise as accurately as possible between the normal unoperated and surgically induced states. Therefore, in order to evaluate the selection of housekeeping genes chosen to normalise between tissue states, SMGB gene expres- 
sion levels were normalised against $A C T B$ and $U B C$, and compared with the observed protein levels previously measured by our group [8]. Here, patterns of $S M G B$ mRNA expression were found to mirror that of their protein whether normalised to ACTB or UBC. However, and importantly, evaluation of the two housekeeping genes for normalisation in the surgically induced atrophic and regenerative states when compared to the normal state indicated that there was an approximately 3 fold underestimation of target gene expression (SMGB) when normalising against $A C T B$ when compared to the more stable $U B C$.

\section{Study Limitation}

An important factor to consider regarding this study is the limited sample number ( $\mathrm{n}=5$ for each group). Nevertheless, even with this low sample number and hence relatively low statistical power, results strongly suggested which genes were displaying the highest stability. This was likely aided by factors such as the high quality/integrity and purity of the RNA samples used, as well as the ability to accurately standardize the amount of RNA put into reactions. Furthermore, rats are relatively homogenous when compared with human samples, therefore, minimizing inter-sample variability.

\section{Conclusion}

Induction of inflammation, atrophy and regeneration in the rat submandibular gland via intra-oral duct ligation serves as a useful model to study gene expression mechanisms. As a consequence, a survey of a small panel of the more commonly used housekeeping genes was carried out. Our study demonstrated the suitability of HPRT to use as a single gene for normalisation within the normal, inflamed and regenerative groups and GAPDH in the atrophic group. However, to further improve accuracy, we recommend normalising to multiple genes as suggested by the geNorm program in this study. These were: ACTB/ $U B C$ in the normal control state, $A C T B / Y W H A Z$ in the inflamed state, $A C T B / H P R T$ in the atrophic state, and $A C T B / G A P D H$ in the regenerative state. The most stable housekeeping gene identified between physiological states (compared to normal) was $U B C$, however, $A C T B$, which was identified as being one of the most stable genes within each state, was found to be one of the most variable.

\section{Methods \\ Samples}

Twenty adult male rats of Wistar (Harlan) strain were used and weighed 250-350 g at the time of experiment. All experimental and terminal procedures were conducted with approval of the local ethics committee and a Home Office license. Animals were divided into 4 groups: control (unoperated), short term ligated (inflamed), long term ligated (atrophic) and de-ligated (regenerative) group. The control gland group underwent no surgical procedure (5 rats), - the ligated group included glands ligated for either $24 \mathrm{hr}$ ( 5 rats) or 2 wks ( 5 rats) using a micro-clip with a plastic tube (see below), - and for the de-ligated group, a separate set of glands ligated for $2 \mathrm{wks}$ were then allowed to recover for a period of exactly 3 days (5 rats). Rats were killed by an overdose of pentobarbitone.

\section{Duct ligation}

Animals were anaesthetised with Ketamine/Xylazine $_{\text {I.P. }}(0.75 \mathrm{ml} / \mathrm{kg}$ of each drug giving a dose of $75+15 \mathrm{mg} /$ $\mathrm{kg}_{\text {I.P., }}$ respectively), given as a mixture of one part of each drug. The main excretory ducts of the right submandibular (RSM) and sublingual glands were carefully dissected with the help of a dissecting microscope through a small incision in the floor of the mouth from an intra-oral approach [22]. The ducts were ligated $5 \mathrm{~mm}$ posterior to the ductal orifice (without including the chorda lingual nerve) with a metal micro-clip (SLS, Vitalitec International, 35680 Domalain, France) and a plastic tube was inserted at the neck of the joint of the clip to avoid any damage and to minimize fibrosis of the ducts [23]. The incision in the floor of the mouth was closed with $8 / 0$ Ethilon suture (Johnson \& Johnson Intl, Brussels, Belgium). Animals were allowed to recover from anaesthesia in a cage maintained in a warm room. Aseptic conditions were used throughout the surgical procedure of duct ligation to reduce the risk of infection. Contralateral glands were not used as controls in this study because compensatory hyperplasia occurred when the opposite gland was extirpated.

\section{Duct de-ligation}

Following ligation, under the same anaesthesia as mentioned earlier, a small incision in the floor of the mouth was made and a careful dissection around the micro-clip was performed without causing any damage to the duct. The clip was held with dissecting forceps and opened with a scalpel (no. 11) blade and then both micro-clip and plastic tube were gently pulled out and the incision closed with 8/0 suture. Animals were allowed to recover from anaesthesia in a warm room. In the case of this study deligation was always carried out following 2 weeks of ligation.

\section{Histochemical staining of tissue samples}

At the end of experiments submandibular glands were removed under terminal anaesthesia, weighed and tissue sections fixed in formal sucrose over night. The rest of the gland was frozen at $-80^{\circ} \mathrm{C}$ for further processing and analysis. Tissue sections were then dehydrated in a series of alcohols, embedded in paraffin wax and $10 \mu \mathrm{m}$ sections stained with Ehrlich Haematoxylin and 1\% Eosin (H \& E) 
for general morphology. For the demonstration of acinar cells and secretory granules Alcian Blue and periodic acid Schiffs stains (AB/PAS) were used [47].

\section{Isolation of RNA and reverse transcription}

Total RNA was isolated from approximately $30 \mathrm{mg}$ of liquid nitrogen preserved submandibular gland tissue and homogenized in $600 \mu \mathrm{l} \mathrm{RNA}-\mathrm{Bee}^{\mathrm{TM}}$ using a $7 \mathrm{ml}$ glass tissue grinder (Wheaton Science Products). The RNeasy Mini Kit (Qiagen) was used for RNA isolation according to the manufacturer's protocol. The RNA yield and the ratio of absorbance at $260 \mathrm{~nm}$ to $280 \mathrm{~nm}\left(\mathrm{~A}_{260} / \mathrm{A}_{280}\right.$ ratio $)$ and $260 \mathrm{~nm}$ to $230 \mathrm{~nm}\left(\mathrm{~A}_{260} / \mathrm{A}_{280}\right.$ ratio $)$ were measured with the NanoDrop ${ }^{\circledR}$ ND-1000 Spectrophotometer (NanoDrop Technologies). The integrity of isolated total RNA was assessed with the RNA 6000 Nano LabChip ${ }^{\circledast}$ kit using the Agilent 2100 Bioanalyzer (Agilent Technologies). The Agilent 2100 Expert software was used to generate an integrity measure for RNA called the RNA Integrity Number (RIN) [27] as a criterion of RNA quality for downstream experiments. The RIN value range from 10 (intact) to 1 (totally degraded) $[27,48]$.

The precipitated RNA was resuspended in $50 \mu \mathrm{l}$ DEPC water and $0.5 \mu \mathrm{g}$ of RNA was reverse transcribed with 200 U Superscript ${ }^{\mathrm{TM}}$ III Reverse Transcriptase (Invitrogen) for $60 \mathrm{~min}$ at $50^{\circ} \mathrm{C}$ using Oligo-dT in $20 \mu \mathrm{l}$ volume. All reverse transcription reactions were carried out in parallel to avoid introducing experimental variation.

\section{Selection of candidate housekeeping genes}

A selection of 7 housekeeping genes (ACTB, GAPDH, $H P R T, Y W H A Z, A R B P, S D H A$ and $U B C$ ) belonging to different functional classes were selected to reduce the chance that these genes might be co-regulated (Table 1). These were pre-designed, gene-specific TaqMan ${ }^{\circledast}$ primer and probe sets (TaqMan ${ }^{\circledast}$ Gene Expression Assays, Applied Biosystems) (Table 2).

\section{Real-time quantitative RT-PCR}

PCR was performed using the ABI Prism ${ }^{\circledast} 7500$ Real-Time PCR System (Applied Biosystems) in 96 well microtitre plates using a final volume of $10 \mu \mathrm{l}$. Amplifications were performed starting with a 2 min activation step for AmparaseUNG at $50^{\circ} \mathrm{C}, 10$ min template denaturation step at $95^{\circ} \mathrm{C}$, followed by 40 cycles of $95^{\circ} \mathrm{C}$ for $15 \mathrm{~s}$ and $60^{\circ} \mathrm{C}$ for $1 \mathrm{~min}$.

\section{Analysis of expression stability}

The Q-RT-PCR raw data was analysed using the SDS 7500 software, (Applied Biosystems). The Q-RT-PCR data was converted to linear values compatible with the geNorm and NormFinder programs. For stability comparisons of candidate housekeeping genes within sample groups, the software geNorm, version 3.4 [29] (Visual Basic applica- tion tool for Microsoft Excel) and NormFinder [30] (a Microsoft Excel Add-in) were used according to developer's recommendations. For comparisons between groups (relative to control), stability was determined by both normalising to total RNA, and via normalising to the geometric mean of multiple housekeeping genes $[29,35]$. In addition, the option in NormFinder to define groups was applied to the different gland states. The software program, SPSS version 15 was used to carry out statistical analysis, namely the Mann-Whitney-U Test (statistical significance $<0.05$ ), of gene expression among experimental groups.

Gene expression analysis of $S M G B$ in the 3 groups (normal, atrophic and regenerative) was carried out using the relative expression software tool $\left(\mathrm{REST}^{\circ}\right)$ [31], developed for group-wise comparison and statistical analysis of relative expression results and includes an efficiency correction for real-time PCR efficiency of the individual transcripts.

\section{Statistical analysis}

Gland weight results were expressed as the mean \pm SEM (Standard Error of the Mean), and were statistically compared by paired Student's t-test. P $<0.05$ was considered statistically significant. The software program, SPSS version 15 was used for further statistical analysis of gene expression using the Mann-Whitney-U Test (statistical significance $<0.05$ ). The REST $^{\circ}$ statistical model uses a pairwise fixed reallocation randomisation test (statistical significance $<0.05$ ).

\section{Abbreviations}

ACTB: $\beta$-actin; ARBP: acidic ribosomal phosphoprotein P0; cDNA: complementary DNA; Ct: cycle threshold; GAPDH: glyceraldehyde 3-phosphate dehydrogenase; HPRT: hypoxanthine-guanine phosphoribosyltransferase; mRNA: messenger RNA; NTC: no template control; PCR: polymerase chain reaction; Q-RT-PCR: quantitative realtime PCR; RIN: RNA integrity number; SDHA: succinate dehydrogenase complex, subunit A, flavoprotein; SMGB: submandibular gland protein B; StdDev: standard deviation; UBC: Ubiquitin C and YWHAZ: tyrosine 3-monooxygenase/tryptophan 5-monooxygenase activation protein, zeta polypeptide.

\section{Authors' contributions}

NS performed all the experimental procedures and was the primary author of the manuscript. GHC participated in the study design and structuring of the manuscript. EC supplied tissue from 2 wk ligated followed by 3 day deligated submandibular glands. SO helped perform the surgical procedures. KLP aided in histological preparation of samples, while GP aided in structuring and editing of the paper. All authors read and approved the manuscript. 


\section{Acknowledgements}

Funding for this work was provided by the Wellcome Trust. The authors would like to thank Dr Ronald Wilson (King's College London, Department of Periodontology) for his generous help with statistical analysis.

\section{References}

I. Bhaskar SN, Lilly GE, Bhussry B: Regeneration of the salivary glands in the rabbit. J Dent Res 1966, 45:37-4I.

2. Tamarin A: Submaxillary gland recovery from obstruction. I. Overall changes and electron microscopic alterations of granular duct cells. J Ultrastruct Res 197I, 34:276-287.

3. Tamarin A: Submaxillary gland recovery from obstruction. II. Electron microscopic alterations of acinar cells. J Ultrastruct Res 1971, 34:288-302.

4. Burford-Mason AP, Cummins MM, Brown DH, MacKay AJ, Dardick I: Immunohistochemical analysis of the proliferative capacity of duct and acinar cells during ligation-induced atrophy and subsequent regeneration of rat parotid gland. J Oral Pathol Med 1993, 22:440-446.

5. Cummins M, Dardick I, Brown D, Burford-Mason A: Obstructive sialadenitis: a rat model. J Otolaryngol 1994, 23:50-56.

6. Takahashi S, Schoch E, Walker NI: Origin of acinar cell regeneration after atrophy of the rat parotid induced by duct obstruction. Int J Exp Pathol I 998, 79:293-301.

7. Ozono S, Sato K, Kondo I, Ito Y, Minabe M: Regeneration of the submandibular gland in rats: immunohistochemical observation of S-phase cells by anti-bromodeoxyuridine monoclonal antibody. Bull Kanagawa Dent Coll 1989, I7:155-158.

8. Cotroneo E, Proctor GB, Paterson KL, Carpenter GH: Early markers of regeneration following ductal ligation in rat submandibular gland. Cell Tissue Res 2008, 332:227-235.

9. Dheda K, Huggett JF, Bustin SA, Johnson MA, Rook G, Zumla A: Validation of housekeeping genes for normalizing RNA expression in real-time PCR. Biotechniques 2004, 37: I I 2-1 I9.

10. Thellin O, Zorzi W, Lakaye B, De BB, Coumans B, Hennen G, Grisar $T$, Igout $A$, Heinen $E$ : Housekeeping genes as internal standards: use and limits. J Biotechnol 1999, 75:291-295.

II. Chen J, Rider DA, Ruan R: Identification of valid housekeeping genes and antioxidant enzyme gene expression change in the aging rat liver. J Gerontol A Biol Sci Med Sci 2006, 6 I:20-27.

12. De Kok JB, Roelofs RW, Giesendorf BA, Pennings JL, Waas ET, Feuth T, Swinkels DW, Span PN: Normalization of gene expression measurements in tumor tissues: comparison of 13 endogenous control genes. Lab lnvest 2005, 85:154-159.

13. Weisser M, Haferlach T, Schoch C, Hiddemann W, Schnittger S: The use of housekeeping genes for real-time PCR-based quantification of fusion gene transcripts in acute myeloid leukemia. Leukemia 2004, 18:155I-I553.

14. Deindl E, Boengler K, van RN, Schaper W: Differential expression of GAPDH and beta3-actin in growing collateral arteries. Mol Cell Biochem 2002, 236:139-I46.

15. Glare EM, Divjak M, Bailey MJ, Walters EH: beta-Actin and GAPDH housekeeping gene expression in asthmatic airways is variable and not suitable for normalising mRNA levels. Thorax 2002, 57:765-770.

16. Hamalainen HK, Tubman JC, Vikman S, Kyrola T, Ylikoski E, Warrington JA, Lahesmaa R: Identification and validation of endog. enous reference genes for expression profiling of $T$ helper cell differentiation by quantitative real-time RT-PCR. Anal Biochem 200I, 299:63-70.

17. Radonic A, Thulke S, Mackay IM, Landt O, Siegert W, Nitsche A Guideline to reference gene selection for quantitative realtime PCR. Biochem Biophys Res Commun 2004, 3 I 3:856-862.

18. Zhong H, Simons JW: Direct comparison of GAPDH, betaactin, cyclophilin, and 28S rRNA as internal standards for quantifying RNA levels under hypoxia. Biochem Biophys Res Commun 1999, 259:523-526.

19. Toegel S, Huang W, Piana C, Unger FM, Wirth M, Goldring MB, Gabor $\mathrm{F}$, Viernstein $\mathrm{H}$ : Selection of reliable reference genes for qPCR studies on chondroprotective action. BMC Mol Biol 2007, 8:13.

20. Torres JM, Gomez-Capilla JA, Ruiz E, Ortega E: Semiquantitative RT-PCR method coupled to capillary electrophoresis to study 5alpha-reductase mRNA isozymes in rat ventral pros- tate in different androgen status. Mol Cell Biochem 2003, 250:125-130

21. Suzuki T, Higgins PJ, Crawford DR: Control selection for RNA quantitation. Biotechniques 2000, 29:332-337.

22. Osailan SM, Proctor GB, McGurk M, Paterson KL: Intraoral duct ligation without inclusion of the parasympathetic nerve supply induces rat submandibular gland atrophy. Int J Exp Pathol 2006, 87:4I-48.

23. Osailan SM, Proctor GB, Carpenter GH, Paterson KL, McGurk M: Recovery of rat submandibular salivary gland function following removal of obstruction: a sialometrical and sialochemical study. Int J Exp Pathol 2006, 87:4II -423.

24. Carpenter GH, Osailan SM, Correia P, Paterson KP, Proctor GB: Rat salivary gland ligation causes reversible secretory hypofunction. Acta Physiol (Oxf) 2007, 189:24I-249.

25. Gupta N, Asp E, Levan G, Mirels L: Structure and chromosomal localization of the rat salivary Psp and Smgb genes. Gene 2000, 243: II-18.

26. Mirels L, Miranda AJ, Ball WD: Characterization of the rat salivary-gland B I-immunoreactive proteins. Biochem J 1998, 330 ( Pt I):437-444.

27. Schroeder A, Mueller O, Stocker S, Salowsky R, Leiber M, Gassmann M, Lightfoot S, Menzel W, Granzow M, Ragg T: The RIN: an RNA integrity number for assigning integrity values to RNA measurements. BMC Mol Biol 2006, 7:3.

28. Walker NJ: Tech.Sight. A technique whose time has come. Science 2002, 296:557-559.

29. Vandesompele J, De PK, Pattyn F, Poppe B, Van RN, De PA, Speleman $F$ : Accurate normalization of real-time quantitative RT-PCR data by geometric averaging of multiple internal control genes. Genome Biol 2002, 3:research0034.I-0034.II.

30. Andersen CL, Jensen JL, Orntoft TF: Normalization of real-time quantitative reverse transcription-PCR data: a model-based variance estimation approach to identify genes suited for normalization, applied to bladder and colon cancer data sets. Cancer Res 2004, 64:5245-5250.

3I. Pfaffl MW, Horgan GW, Dempfle L: Relative expression software tool (REST) for group-wise comparison and statistical analysis of relative expression results in real-time PCR. Nucleic Acids Res 2002, 30:e36.

32. Selvey S, Thompson EW, Matthaei K, Lea RA, Irving MG, Griffiths LR: Beta-actin--an unsuitable internal control for RT-PCR. Mol Cell Probes 200I, 15:307-3II.

33. Tricarico C, Pinzani P, Bianchi S, Paglierani M, Distante V, Pazzagli M, Bustin SA, Orlando C: Quantitative real-time reverse transcription polymerase chain reaction: normalization to $r R N A$ or single housekeeping genes is inappropriate for human tissue biopsies. Anal Biochem 2002, 309:293-300.

34. Cai JH, Deng S, Kumpf SW, Lee PA, Zagouras P, Ryan A, Gallagher DS: Validation of rat reference genes for improved quantitative gene expression analysis using low density arrays. Biotechniques 2007, 42:503-5I2.

35. P. W, Brereton HM, Coster DJ, Williams KA: Stability of housekeeping gene expression in the rat retina during exposure to cyclic hyperoxia. Mol Vis 2007, 13:1508-1515.

36. Al-Bader MD, Al-Sarraf HA: Housekeeping gene expression during fetal brain development in the rat-validation by semiquantitative RT-PCR. Brain Res Dev Brain Res 2005, I 56:38-45.

37. Tanic N, Perovic M, Mladenovic A, Ruzdijic S, Kanazir S: Effects of aging, dietary restriction and glucocorticoid treatment on housekeeping gene expression in rat cortex and hippocampus-evaluation by real time RT-PCR. J Mol Neurosci 2007, 32:38-46.

38. Baker OJ, Camden JM, Ratchford AM, Seye CI, Erb L, Weisman GA Differential coupling of the P2YI receptor to Galphal 4 and Galphaq/I I proteins during the development of the rat salivary gland. Arch Oral Biol 2006, 5 I:359-370.

39. Shimizu K, Murata T, Hiramoto K, Sugiyama T, Nakagawa T, Manganiello VC, Tagawa T: Expression of cyclic nucleotide phosphodiesterase $3 \mathrm{~A}$ in isolated rat submandibular acini. Arch Oral Biol 2006, 51:83-88

40. Reina S, Orman B, Anaya JM, Sterin-Borda L, Borda E: Cholinoreceptor autoantibodies in Sjogren syndrome. J Dent Res 2007, 86:832-836 
4I. Tsukinoki K, Saruta J, Sasaguri K, Miyoshi Y, Jinbu Y, Kusama M, Sato $S$, Watanabe $Y$ : Immobilization stress induces BDNF in rat submandibular glands. J Dent Res 2006, 85:844-848.

42. Kajikawa $S$, Kigami D, Nakayama $H$, Doi K: Changes in submaxillary gland gene expression in F344 rats by multiple dosing of theophylline. Exp Anim 2006, 55: I43-I 46.

43. Norberg LE, Abok K, Lundquist PG: Effects of ligation and irradiation on the submaxillary glands in rats. Acta Otolaryngol 1988, 105: $181-192$.

44. Shiba R, Hamada T, Kawakatsu K: Histochemical and electron microscopical studies on the effect of duct ligation of rat salivary glands. Arch Oral Biol 1972, 17:299-309.

45. Scott J, Liu P, Smith PM: Morphological and functional characteristics of acinar atrophy and recovery in the duct-ligated parotid gland of the rat. J Dent Res 1999, 78:17II-1719.

46. Silver N, Best S, Jiang J, Thein SL: Selection of housekeeping genes for gene expression studies in human reticulocytes using real-time PCR. BMC Mol Biol 2006, 7:33.

47. Mowry RW: Observations on the use of sulfuric acid in ether for the sulfation of hydroxyl groups in tissue sections. J Histochem Cytochem 1958, 6:82-83.

48. Imbeaud S, Graudens E, Boulanger V, Barlet X, Zaborski P, Eveno E, Mueller O, Schroeder A, Auffray C: Towards standardization of RNA quality assessment using user-independent classifiers of microcapillary electrophoresis traces. Nucleic Acids Res 2005, 33:e56.

Publish with Bio Med Central and every scientist can read your work free of charge

"BioMed Central will be the most significant development for disseminating the results of biomedical research in our lifetime. "

Sir Paul Nurse, Cancer Research UK

Your research papers will be:

- available free of charge to the entire biomedical community

- peer reviewed and published immediately upon acceptance

- cited in PubMed and archived on PubMed Central

- yours - you keep the copyright

Submit your manuscript here:

http://www.biomedcentral.com/info/publishing_adv.asp
BiolMedcentral 